\title{
Representações sociais da deficiência nas famílias: um estudo comparativo ${ }^{1}$
}

\author{
Social representations of disability in families: a comparative study \\ Marla Bernardes Carmino dos Santos Dias Luna² \\ Luciene Alves Miguez Naiff ${ }^{3}$
}

\begin{abstract}
RESUMO: O principal objetivo deste estudo foi identificar as representações sociais da deficiência em famílias, considerando que a deficiência resulta da interação entre pessoas com deficiência, as barreiras comportamentais e as ambientais que impedem sua participação plena e eficaz na sociedade de forma igualitária. Optou-se comparar a representação de dois tipos de grupos familiares: um grupo familiar no qual há convívio direto com pessoas com deficiência e outro grupo familiar em que não há convívio direto com pessoas com deficiência. Foi utilizado o referencial teórico da Teoria das Representações Sociais em especial a contribuição da Abordagem estrutural de modo a identificar e comparar os prováveis núcleos centrais das representações entre os grupos estudados. Para tanto, utilizou-se questionários com questões fechadas e abertas e tarefas de evocação livre acerca de dois objetos: Deficiência e Pessoa com Deficiência. A pesquisa foi realizada com 108 famílias residentes no Estado do Rio de Janeiro. Os resultados apontam as representações sociais nas famílias em convívio direto com as pessoas com deficiência ligadas aos aspectos da dinâmica cotidiana, dos direitos e da visão de compreender a pessoa com deficiência como sujeito. As famílias que não apresentam o convívio direto possuem representações sociais relacionadas a sentimentos de pena, compaixão, questões ligadas ao corpo e a falta, o que gera preconceitos e discriminações. Como semelhança os grupos apontaram a dificuldade vivida pela pessoa com deficiência para garantir seus direitos, a falta de infraestrutura/acessibilidade e de políticas públicas efetivas.
\end{abstract}

Palavras-chave: representações sociais; pessoa com deficiência; família; preconceito; direitos sociais.

\begin{abstract}
The main objective of this study was to identify the social representations of disability in families, considering that disability results from the interaction between persons with impairments and attitudinal and environmental barriers that hinders their full and effective participation in society on an equal basis. We chose to compare the representation of two types of family groups: a family group in which there is direct contact with people with disabilities and another family group in which no direct contact with people with disabilities. The theoretical framework of the Theory of Social Representations in particular the contribution of the structural approach to identify and compare the probable central representations of nuclei between groups was used. For this, we used questionnaires with closed and open questions and tasks on free recall of two objects: Disability and Persons with Disabilities. The survey was conducted with 108 families residing in the State of Rio de Janeiro. The results indicate the social representations in families with direct contact to persons with disabilities related to aspects of everyday dynamics of rights and the vision to understand the person with disabilities as well as their status as subject. Families that do not have this reality have social representations related to feelings of shame, compassion, connected body issues and lack, which creates prejudice and discrimination. How similarity pointed out the difficulty experienced by people with disabilities to ensure their rights, lack of infrastructure / accessibility and effective public policy.
\end{abstract}

Keywords: social representations; person with disabilities; family; prejudice; social rights.

\footnotetext{
$1 \mathrm{O}$ presente estudo recebeu apoio da Fundação Carlos Chagas Filho de Amparo à Pesquisa do Estado do Rio de JaneiroFAPERJ através de bolsa de mestrado.

2 Mestre em Psicologia pela Universidade Federal Rural do Rio de Janeiro - Seropédica, Rio de Janeiro, Brasil. E-mail: marlapsic@gmail.com.

${ }^{3}$ Doutora em Psicologia; Professora do Programa de pós-graduação stricto sensu em Psicologia da Universidade Federal Rural do Rio de Janeiro - Seropédica, Rio de Janeiro, Brasil.
} 


\section{Introdução}

De cunho psicossocial, o presente estudo apresenta-se referenciado na Teoria das Representações Sociais tendo como temáticas a deficiência, a pessoa com deficiência e seu impacto nas famílias. As pessoas com deficiência e a deficiência no Brasil nos dias atuais são objetos de reflexão, legislação, discussões e estão disponíveis nas mídias, na ciência, nas leis e nas conversações de uma maneira geral. A pauta dos direitos humanos civis e sociais nunca abarcou tantas e diversas minorias que antes tinham suas reinvindicações negadas ou silenciadas.

Nesse cenário, a busca por sentidos socialmente compartilhados e que permitam posicionamentos sociais aceitos entre pares é campo legítimo e fértil para a produção das representações sociais, propostas por Serge Moscovici (Jodelet, 2001).

Considerando ainda a relação que existe entre o pensamento social e as práticas, podemos apontar a importância de identificar o conhecimento do senso comum que circula entre indivíduos que convivem ou não com a deficiência, na maneira que lidam com essas questões em seu cotidiano, ampliando com isso o debate e as possíveis ações de apoio e inclusão.

Portanto, a escolha do referencial teórico na Teoria das Representações Sociais se justifica pelo objetivo de identificar os aspectos do pensamento social que circulam nos grupamentos familiares acerca da deficiência e permitirá, em última análise, conhecer como esse conhecimento socialmente partilhado pode orientar comportamentos. Jodelet (2005) em seu trabalho acerca da loucura e das representações sociais já aponta pistas de que a forma que a pessoa com deficiência é percebida na sociedade orienta práticas muitas vezes discriminatórias oriundas dos receios e desconhecimento que a não familiaridade provoca.

Segundo o Relatório Mundial da Deficiência (2012), a deficiência atualmente é vista como um aspecto da condição humana. Ou seja, de uma maneira ou de outra esta condição deverá afetar a todos, seja através de uma deficiência temporária ou permanente, seja através das consequências do próprio envelhecimento. Esta nova agenda social coloca a deficiência como um aspecto que deverá ser cada vez mais o foco de políticas públicas, de modo a criar condições de vida dignas a população como um todo.

Ao evidenciar a família no presente estudo, considera-se que este é o principal grupo social influenciado pela existência da pessoa com deficiência entre seus membros. A família exerce diversos papéis, dentre eles a socialização, a proteção e o cuidado. Assim, acredita-se que na família é que a questão da deficiência toma sentidos e significados específicos tornando-se, portanto, um grupo privilegiado na produção de representações sociais (Naiff, Sá \& Naiff, 2005).

\section{A Teoria das representações sociais}

Em sua obra Psychanalyse son image et son public Moscovici (1961/2012) redimensiona a visão das Representações Coletivas de Durkheim apresentando a construção do pensamento social a serviço de um tempo em que as mudanças ocorrem de modo mais dinâmico do que aqueles estudados por Durkheim. Moscovici (1981) descreve as representações sociais como:

Um conjunto de conceitos, proposições e explicações originado na vida cotidiana no curso de comunicações interpessoais. Elas são o equivalente, em nossa sociedade, dos mitos e sistemas de 
crenças das sociedades em tradicionais; podem também ser vistas como a versão contemporânea do senso comum (p. 181).

De acordo com Vala (2004), enquanto para Durkheim as representações coletivas são mais rígidas e permeiam toda uma coletividade independente da cultura e composição sócio-histórica desse grupo, Moscovici (2012) as chamará de representações sociais e as relacionará com os grupos, suas especificidades e as demandas de seu cotidiano.

Um dos importantes tópicos da TRS diz respeito ao aspecto dialético existente entre o conceito e a percepção: "a representação, como pensamos, não é a instância intermediária, mas um processo que, de alguma forma, torna o conceito e a percepção intercambiáveis pelo fato de se engendrarem reciprocamente". (Vala, 2004, p. 53). O que equivale dizer que não há, segundo Moscocivci (2012), uma cisão entre objeto e representação. Ou seja, o objeto é a representação do mesmo para o sujeito.

Jodelet (2011) afirma que o conceito de representação social foi renovador para a Psicologia Social ampliando o escopo da área e promovendo a aproximação com as ciências sociais. Para a autora é preciso dizer que:

as representações devem ser estudadas articulando-se elementos afetivos, mentais e sociais e integrando - ao lado da cognição, da linguagem e da comunicação - a consideração das relações sociais que afetam as representações e a realidade material, social e ideativa sobre a qual elas têm de intervir (p. 26).

Jodelet (2001) ainda diz que a representação social é "uma forma de conhecimento, socialmente elaborada e partilhada, com um objetivo prático e que contribui para a construção de uma realidade comum a um conjunto social" (p. 22).

Diante das definições descritas acima sobre representações sociais, três pontos de vista podem ser considerados: o primeiro é o epistemológico, focalizado nos processos cognitivos; o segundo é o psicodinâmico, onde a ênfase está em mecanismos intrapsíquicos e o último o social ou coletivo, que se refere à análise dos dois processos, o cognitivo e o psicodinâmico, acrescido da análise do pertencimento, da participação social e cultural do sujeito (Sá, 1996).

De acordo com Palmonari e Cerrato (2011), três aspectos também colaboraram no marco da construção da Teoria das Representações Sociais: a aquisição das percepções e crenças através da interação social; a importância das crenças e das representações e o papel delas na vida do sujeito. A partir dessas fundamentações dá-se mais importância às relações e interações sociais às relações sujeito/objeto e surge então a proposta de Moscovici em centralizar a pesquisa no plano coletivo. Assim, a pesquisa psicossocial além de envolver os processos e os conteúdos do pensamento social, enfatiza também as relações sociais, intersubjetivas e as relações entre sujeito/objeto.

Outras contribuições vieram complementar a Teoria Moscoviciana. Nos ateremos a abordagem estrutural que corresponde a escolha feita na presente pesquisa.

\section{Abordagem estrutural das representações sociais}

A abordagem estrutural considera a organização dos cognemas em uma representação social. Abric argumenta que conhecer uma representação social não se resume em levantar seu conteúdo, mas revelar sua estrutura (Lo Monaco \& Lheureux, 2007; Lo Monaco, Lheureux \& Halimi-Falkowicz, 2008).

Segundo Wachelke e Wolter (2011): 
A abordagem estrutural é uma escola dentre as diversas existentes para o estudo do fenômeno das representações sociais. Trata-se de uma perspectiva que concebe representações sociais como estruturas de conhecimento sobre temas da vida social, compartilhadas por grupos e formadas por elementos cognitivos ligados entre si. A principal teoria da abordagem estrutural é a Teoria do Núcleo Central que defende que as representações sociais são um duplo sistema formado por dois tipos de elementos: um núcleo central e o sistema periférico (p. 521).

Abric (1994) afirma que as representações sociais estão organizadas em torno de um núcleo e este determina sua organização interna e significação. O núcleo é como um subconjunto da representação, pois a ausência dele daria uma significação totalmente diferente à representação. Sobre o núcleo central afirma Abric (1994):

la organización de una representación presenta uma modalidad particular, específica: no únicamente lós elementos de la representación son jerarquizados sino además toda representación está organizada alrededor de um núcleo central, constituído por uno o vários elementos que dan su significación a la representación" (p. 18).

O núcleo central, segundo Abric (1994), é um elemento estável que estrutura a representação e possui duas funções essenciais: a) a função geradora, que cria ou transforma os elementos constitutivos da representação; e b) a função organizadora que determina a natureza dos laços que unem entre si os elementos da representação.

O núcleo central garante a estabilidade e homogeneidade da representação. Abric afirma que: "Luego el núcleo es simple, concreto, gráfico y coherente, corresponde igualmente al sistema de valores al cual se refiere el individuo, es decir que lleva la marca de la cultura y las normas del entorno social" (Abric, 1994, p. 20).

Além do núcleo central, as representações sociais apresentam o sistema periférico e como o nome já diz encontra-se ao redor do sistema central. Nesse sentido, podemos dizer que as representações sociais operam em um duplo sistema.

Segundo Jodelet (2001), nos elementos periféricos há a presentificação de uma dada situação, indicando o que é de certo modo normal e o que não é normal ou adequado naquele momento. Portanto, o sistema periférico se atualiza mais constantemente e sofre maior influencia do momento presente.

O sistema periférico, conforme descreve Abric (1994), exerce as funções de concretização, regulação e defesa. A primeira função de concretização concede a compreensão da representação em termos mais acessíveis e concretos. A segunda função, a reguladora, faz com que informações novas possam ser integradas ou não, devido à permeabilidade dos elementos periféricos. A terceira função de defesa, como já se diz, protege o núcleo central das transformações e interpretações novas, pois essas ocorrem no nível periférico.

Para Jodelet (2001) as ideologias estão no sistema periférico, ou seja, não atingem o núcleo central de uma representação. No entanto, as práticas sociais estão diretamente ligadas ao núcleo central e podem ser responsáveis por mudanças nas representações sociais. Se as práticas sociais estiverem em contradição com as representações, dependendo do grau de antítese encontrado, podem haver rupturas mais ou menos impactantes que modificarão de forma definitiva ou não as representações sociais de um grupo. Por exemplo, novas descobertas acerca de um assunto que modifiquem práticas podem levar a mudanças nas representações sociais.

Representações sociais e práticas são conceitos que devem ser relacionados em estudos científicos de modo a permitir estabelecer, entre outras coisas, relações que 
justifiquem ações contra normativas em um ambiente em que há um patrulhamento de discursos mais preconceituosos (Pereira \& Vala, 2010).

\section{Implicações sobre a deficiência e a família}

A deficiência enquanto um fenômeno social ainda hoje é um desafio a se enfrentar. Esse argumento não diz respeito somente às necessidades de acessibilidade relacionadas às limitações físicas por ela causadas, mas também às consequências que a produção desse conceito gera nas relações interpessoais das pessoas com deficiência e de seus familiares.

O sujeito com uma deficiência é um ser social, histórico-cultural, com habilidades e personalidade que lhe são singulares e que estão além da deficiência em si. No entanto, a falta de informações precisas e práticas sociais inclusivas em nossa história recente acentua os preconceitos e a discriminação.

A deficiência é um conceito em evolução, mas deve ser realçado também que "a deficiência resulta da interação entre pessoas com deficiência e as barreiras comportamentais e ambientais que impedem sua participação plena e eficaz na sociedade de forma igualitária" (Relatório Mundial sobre a Deficiência, 2012. p. 4). Definir a deficiência como uma interação significa que a "deficiência" não é um atributo da pessoa. O progresso na melhoria da participação social pode ser realizado lidando com as barreiras que afetam pessoas com deficiência na vida diária (Relatório Mundial sobre a Deficiência, 2012).

A ONU em 2007 estabelece a Convenção dos Direitos das Pessoas com Deficiência, que passa a vigorar assegurando dentre outros direitos: o da igualdade de oportunidade em emprego, a não discriminação, a adaptação de instrumentos e o exercício do direito de ir e vir. A deficiência nesse contexto é tratada da seguinte maneira:

Pessoas com deficiência são aquelas que têm impedimentos de longo prazo de natureza física, mental, intelec-tual ou sensorial, os quais, em interação com diversas barreiras, podem obstruir sua participação plena e efetiva na sociedade em igualdades de condições com as demais pessoas (Brasil, 2008, p. 16).

A família junto com as instituições de asilamento durante muito tempo foram os únicos ambientes em que a deficiência era visível. Existia um vazio social, uma invisibilidade envolta em desconhecimentos, medos, e, muitas vezes por parte da família, vergonha e tentativa de proteção dos olhares alheios.

Atualmente vemos uma redescoberta dessa parcela da população, como se ela passasse a existir a partir do momento que percebemos suas necessidades. A inclusão é hoje uma bandeira social de grande repercussão mundial, no entanto, a família ainda é o principal lócus de acesso, cuidados, proteção, respeito e existência das pessoas com deficiência.

Encontramos em Ariès (1981) a compreensão que nos interessa acerca da família, ou seja, a família é uma construção social e cultural e sua definição está a serviço de seu tempo e história. Desta forma, nota-se que família na concepção mais moderna é quem a pessoa define e aponta como sendo, independente dos laços sanguíneos ou de residirem no mesmo espaço físico.

O interesse em evidenciar a família está também na evolução dos estudos e pesquisas de Goffman (1980), Glat (1994, 1996), Omote (1994) e Cavalcante (2003) que enfatizam o papel, a função e as fases que a família passa de maneira geral por ser o grupo primário de 
socialização do sujeito, destacando que nas famílias onde há alguma pessoa com deficiência algumas dessas fases são marcadas pelos desafios reais e simbólicos vividos.

A partir das considerações expostas acima e da importância que os estudos psicossociais podem trazer na ampliação dos conhecimentos sobre a percepção da deficiência na sociedade brasileira, o principal objetivo deste estudo é identificar as representações sociais sobre a deficiência e a pessoa com deficiência nas famílias. Optou-se comparar a representação de dois tipos de grupos familiares: um grupo familiar no qual a deficiência é presente em algum membro mais próximo e em outro grupo familiar no qual a deficiência em si não está presente.

A comparação das representações desses dois grupos evidenciou alguns objetivos específicos, como: perceber as diferenças de representação entre os grupos pesquisados e como elas acontecem; que tipo de influência predominante aparece na construção das representações nos dois grupos. Outro ponto que merece destaque é a diferenciação entre os objetos de estudo: deficiência e pessoa com deficiência de forma a perceber o pensamento social dos grupos pesquisados quando introduzimos a noção da pessoa em relação a deficiência e esta em si.

\section{Método}

\section{Procedimentos}

Aplicou-se um questionário com questões fechadas e abertas e uma tarefa de evocação livre. Na tarefa de evocação livre foram utilizados dois termos indutores: deficiência e pessoa com deficiência. Nas questões abertas indagamos acerca das facilidades e dificuldades enfrentadas no cotidiano, de forma a capturar algumas dimensões da vida prática no que envolve viver com deficiência. As questões fechadas compuseram as informações sócio demográficas.

O estudo revela as representações sociais em dois tipos familiares, a família que está em convívio direto com alguma pessoa com deficiência e a família que não está em convívio direto com alguma pessoa com deficiência. O critério da escolha do familiar participante da pesquisa deu-se através da eleição da própria família em designar a pessoa mais diretamente envolvida na função de cuidador (a) na família, ou seja, àquela pessoa que se aproxima mais dos cuidados pessoais de uma pessoa que depende de outrem por algum motivo: faixa etária, condição, desenvolvimento e outros.

Utilizou-se também para a realização deste estudo a apresentação do Termo de Livre Consentimento às famílias que foi assinado pelo representante escolhido. $O$ estudo foi submetido e aprovado pelo Comitê de Ética da Universidade Federal Rural do Rio de Janeiro, processo 23083.003355/2013-14 atendendo os princípios éticos de acordo com a Resolução 196/96 que regulamenta os procedimentos de pesquisa envolvendo seres humanos.

\section{Participantes}

Participaram da pesquisa 108 indivíduos representantes de famílias divididas em dois grupos: 54 representantes de famílias sem convívio com pessoas com deficiência em seu núcleo mais íntimo e 54 representantes de famílias com convívio em seu núcleo. 
Para melhor apresentar os grupos utilizaremos as siglas GCD (para os representantes do Grupo com convívio direto) e GSD (para os representantes sem convívio direto).

No GCD $72,2 \%$ dos sujeitos são do sexo feminino e outros $27,8 \%$ do sexo masculino. Em relação a renda familiar $40,4 \%$ dos participantes têm a renda entre 4-6 salários mínimos, $30,8 \%$ com 07 ou mais salários mínimos e $28 \%$ estão com renda abaixo a 04 salários mínimos. A faixa etária de 36 anos em diante compreende $65,9 \%$ dos pesquisados, a faixa etária de 25-35 anos $25,9 \%$ e somente $7,4 \%$ participantes estão com idade abaixo de vinte anos.

No GSD $77,8 \%$ sujeitos são do sexo feminino e $22,2 \%$ do sexo masculino. Quanto à renda familiar há 38,5\% dos participantes entre 4-6 salários, 38,5\% cuja renda é de 07 ou mais salários e os outros $23,1 \%$ dos sujeitos estão abaixo de 04 salários mínimos. Em relação a idade $72,2 \%$ estão entre 25 e 45 anos. Acima e abaixo dessa faixa temos $11,1 \%$ em cada subgrupo.

$\mathrm{Na}$ maioria de ambos os grupos representantes escolhidos foram do sexo feminino, reproduzindo uma visão de gênero perpetuada em diversas pesquisas e na concepção histórica da mulher no Brasil (Rocha-Coutinho, 1994; Naiff, Sá \& Naiff, 2005; Freire-Costa, 1979).

A renda foi na maioria superior a 4 salários mínimos, sendo significativa a frequência de famílias com renda acima de 7 salários mínimos. Isso se deve ao acesso a amostra em uma instituição de atendimento de reabilitação voltada a população de renda média.

\section{Resultados}

Apresentaremos os resultados iniciando pelas evocações livres que nos fornece a provável estrutura das representações sociais organizada em um sistema central e um sistema periférico (Sá, 1996). Os dados foram rodados pelo software Evoc que combina a frequência com a ordem de importância dos elementos (Vérgès, 2005).

Como propomos a comparação entre dois grupos e dois objetos, obtivemos 4 configurações de levantamento de representações sociais assim descritas: a) GCD acerca da deficiência; GCD acerca da pessoa com deficiência; GSD acerca da deficiência; GSD acerca da pessoa com deficiência.

Os elementos dos prováveis núcleos centrais nas 4 configurações foram: a) GSD em relação a pessoa com deficiência: dificuldade, ajuda, superação, exclusão, limitação; b) GSD em relação a deficiência: dificuldade, ajuda, cuidado, limitação, preconceito, falta e incapacidade; c) GCD em relação a pessoa com deficiência: ajuda, denominações sobre deficiências, dificuldades, amor; d) GCD em relação a deficiência: amor, dificuldades, denominações sobre deficiências e superação. Apresentaremos os pontos convergentes entre os elementos que apareceram nas configurações identificadas. A tabela 1 apresenta de que forma os elementos dos prováveis núcleos centrais das representações sociais identificadas em cada uma das configurações aparece em relação às outras.

Ao analisar as evocações livres, observa-se que o elemento dificuldade aparece em todos os núcleos centrais dos grupos e objetos da pesquisa. Este elemento comum demonstra ser um analisador importante que para os grupos representa a unidade de sentido por trás das representações sociais acerca da deficiência e da pessoa com deficiência. 
O elemento amor também está presente fortemente nos grupos, sendo que para o GCD ele se caracteriza como elemento do núcleo central e para o GSD como elemento de primeira periferia.

O elemento limitação é um elemento comum aos grupos e aos objetos em pesquisa, sendo que para o GCD está na zona de contraste enquanto que no GSD configura como elemento do núcleo central.

Outro elemento presente nas evocações dos grupos é ajuda, sendo núcleo central nas representações sociais do objeto pessoa com deficiência nos dois grupos pesquisados e também aparece no núcleo central em relação a deficiência no GSD.

O cognema preconceito aparece na zona de contraste nas representações da pessoa com deficiência no GCD e nas representações da deficiência na segunda periferia. No GSC o elemento Preconceito apresenta-se como elemento de contraste nas representações sociais da pessoa com deficiência e como elemento pertencente ao núcleo central nas representações da deficiência.

Superação é também um cognema comum em ambos os grupos e objetos. No GCD o elemento está presente na primeira periferia nas representações sociais do objeto pessoa com deficiência e no núcleo central em relação as representações sociais da deficiência. No GSD aparece no núcleo central nas representações da pessoa com deficiência e no quarto quadrante em relação a deficiência.

As mudanças na estrutura apontam pistas de dinamicidade das representações sociais, segundo Wachelke (2013):

Uma estrutura é um sistema formado por unidades interconectadas, incluindo aí as leis que regulam seu funcionamento. Tratar uma estrutura como um sistema significa que uma mudança em um componente pode ocasionar modificações em qualquer outro elemento. (p.135)

Tabela 1- Organização dos elementos dos prováveis núcleos centrais das representações sociais nas configurações propostas

\begin{tabular}{|c|c|c|c|c|}
\hline \multirow[t]{2}{*}{ Grupo } & GCD/ & GCD/ & GSD/ & GSD/ \\
\hline & Pessoa com Deficiência & Deficiência & $\begin{array}{l}\text { Pessoa com } \\
\text { Deficiência }\end{array}$ & Deficiência \\
\hline \multicolumn{5}{|l|}{ Elemento } \\
\hline Dificuldade & Núcleo central & Núcleo central & Núcleo central & Núcleo central \\
\hline Amor & Núcleo central & Núcleo central & 1a periferia & 1a periferia \\
\hline Limitação & zona de contraste & zona de contraste & Núcleo central & Núcleo central \\
\hline Ajuda & Núcleo central & Não apareceu & Núcleo central & Núcleo central \\
\hline Preconceito & zona de contraste & 2a periferia & zona de contraste & Núcleo central \\
\hline Superação & 1a periferia & Núcleo central & Núcleo central & 2a periferia \\
\hline Exclusão & Não apareceu & Não apareceu & Núcleo central & Não apareceu \\
\hline Cuidado & Não apareceu & Não apareceu & Não apareceu & Núcleo central \\
\hline Falta & Não apareceu & Não apareceu & Não apareceu & Núcleo central \\
\hline Incapacidade & Não apareceu & Não apareceu & Não apareceu & Núcleo central \\
\hline $\begin{array}{l}\text { Denominações } \\
\text { variadas para } \\
\text { deficiências }\end{array}$ & Núcleo central & Núcleo central & Não apareceu & Zona de contraste \\
\hline
\end{tabular}


Em resumo podemos perceber na Tabela 1 a dificuldade como o elemento comum a todos os subgrupos, o amor compondo o núcleo central das representações sociais no GCD em relação a ambos os objetos, a limitação e a ajuda compondo o núcleo central no GSD em relação aos dois objetos propostos.

Existe ainda certa confusão entre a pessoa com deficiência e a deficiência em si, ainda que tenhamos encontrado elementos que os diferencie em relação aos grupos estudados, pois demonstram uma tendência em perceber a pessoa como sujeito e a deficiência como uma condição, esta é, portanto, a proposta de uma terminologia mais adequada e menos preconceituosa à pessoa com deficiência para que o sujeito seja visto para além de qualquer condição (Sassaki, 2003).

As questões abertas foram analisadas inspiradas na proposta de Análise de Conteúdo de Bardin (2010), sendo categorizadas a partir das unidades de contexto e de registro encontradas. Quanto ao Tema Fatores que dificultam a vida das pessoas com deficiência as categorias encontradas no GCD com maior frequência foram: Relações de Convivência com $40,6 \%$ que abrange os comportamentos sociais como preconceito, indiferença, isolamento, pena, nojo às pessoas com deficiência; a Categoria Políticas Públicas com 19,7\% abordando saúde, educação e políticas direcionadas a realidade enfrentada pelas pessoas com deficiência, a Categoria Infraestrutura-Acessibilidade com 19,7\%, que contempla os lugares abertos e fechados não adaptados as pessoas com deficiência e a categoria Informação com $13,5 \%$.

Tabela 2- Categorias GCD em relação as dificuldades

\begin{tabular}{cc}
\hline Categorias & Frequência \\
\hline Relações de convivência & $40,60 \%$ \\
Infraestrutura/acessibilidade & $19,70 \%$ \\
Políticas públicas & $19,70 \%$ \\
Informações & $13,50 \%$ \\
Outros & $7,20 \%$ \\
\hline
\end{tabular}

No GSD as categorias mais fortemente apontadas foram: Relações de Convivência com 60\%, seguido da categoria Políticas Públicas com 19,9\% em relação ao Tema Fatores que dificultam a vida das pessoas com deficiência, como pode se observar na tabela 3 :

Tabela 3 - Categorias GSD em relação as dificuldades

\begin{tabular}{cc}
\hline Categorias & Frequência \\
\hline Relações de Convivência & $60,00 \%$ \\
Políticas Públicas & $24,50 \%$ \\
Infraestrutura/acessibilidade & $6,10 \%$ \\
Informação & $4,60 \%$ \\
Outros & $4,60 \%$ \\
\hline
\end{tabular}

Em relação ao Tema Fatores que facilitam a vida das pessoas com deficiência para o GSC, conforme observamos na Tabela 4, as categorias foram: Relações de Convivência 
25,6\%, apropriando-se de comportamentos sociais de cunho positivo, como o amor, a empatia, solidariedade, compreensão dentre outros; a categoria Políticas Públicas o envolvimento do Governo com a causa das pessoas com deficiência inclusive nas macro áreas de Educação e saúde foi de 38,9\% e Infraestrutura-Acessibilidade com 15,8\%.

Tabela 4 - Categorias GSD em relação as facilidades

\begin{tabular}{cc}
\hline Categorias & Frequência \\
\hline Políticas públicas & $38,90 \%$ \\
Relações de Convivência & $25,60 \%$ \\
Infraestrutura/Acessibilidade & $15,80 \%$ \\
Informação & $8,50 \%$ \\
Outros & $7,20 \%$ \\
\hline
\end{tabular}

No GCD em relação ao Tema exposto acima foram: $37,2 \%$ na categoria Políticas públicas, $18,6 \%$ Infraestrutura-Acessibilidade, e 12,7\% na categoria Relações de Convivência. $\mathrm{O}$ que revela que para este grupo os fatores que facilitam a vida da pessoa com deficiência estão mais voltados as tarefas de rotina e que não se espera só empatia, amor ou respeito, mas condições favoráveis de dignidade e de cidadania, conforme observamos na Tabela 5.

Tabela 5 - Categorias GCD em relação as facilidades

\begin{tabular}{cc}
\hline Categorias & Frequência \\
\hline Políticas Públicas & $37,20 \%$ \\
Infraestrutura/Acessibilidade & $18,60 \%$ \\
Relações de convivência & $12,70 \%$ \\
Onformação & $9,30 \%$ \\
\hline
\end{tabular}

\section{Discussão e análise dos dados}

Percebe-se que existem nas representações sociais identificadas elementos comuns aos grupos que ainda estão arraigados ao fator histórico que permeia a temática Deficiência. São esses elementos carregados de valores do discurso biomédico e de reabilitação, característico do caminho percorrido pela história brasileira em se tratando de deficiência. $A$ deficiência historicamente foi tratada como um fator de cuidado e não de autonomia. Portanto, o pensamento social está norteado por conceitos como cuidar, reabilitar, superar e outros elementos que reforçam a dependência física e deixam escapar as potencialidades e a dimensão subjetiva do indivíduo com deficiência. (Lanna Júnior, 2010; Diniz, Barbosa \& Santos, 2009).

O pensamento social identificado nos grupos confere um peso importante a dificuldade relacionada tanto a deficiência em si quanto a pessoa com deficiência. Nesse sentido, é importante salientar que a luta dos movimentos sociais pelos direitos da pessoa com deficiência é a total aderência das diversidades apresentadas pelos seres humanos de forma a uma vida plena e fácil para todos, porque todos são diferentes e possuem necessidades que são específicas. Enquanto as dificuldades ainda apontam para problemas 
de relações de convivência social, revelando o quanto os grupos percebem o preconceito a ser transposto, nas facilidades apontadas percebemos o peso dado as políticas públicas como responsáveis por facilitar a vida das pessoas e das famílias. Esse fator pode indicar uma visão mais crítica, de atribuição de responsabilidade mais apropriada na conjuntura atual.

Ainda se fala em amor quando se pensa nas pessoas com deficiência. Em recente pesquisa feita sobre a inclusão educacional, amor foi um dos elementos mais pregnantes nas representações sociais de professores de escolas públicas (Almeida \& Naiff, 2009). O elemento Amor nas questões abertas está presente nos discursos atrelado ao cuidado, a paciência e a outros comportamentos, ato que remete ao comportamento no século XIX, período em que cabia a igreja cuidar das pessoas com deficiência, pois necessitavam de atenção, cuidado, amor, com o comprometimento de fraternidade pelas almas (Silva, 1987). Somente na análise mais aprofundada das unidades de contexto nas questões abertas referentes ao GCD percebemos um tom de crítica na ideia do amor como bom samaritanismo, expressando uma forma de preconceito velado.

Limitação foi outro elemento comum aos grupos e que se apresenta muito fortemente no GSD. A deficiência como limitação ainda é um elemento presente no discurso do senso comum e compõe a ideia que as pessoas fazem que engloba ainda a pena e a compaixão. Logo, as representações sociais ainda absorvem um olhar para as pessoas com deficiência circunscrito na leitura do corpo, do físico, do biológico. Como afirma Diniz, Barbosa \& Santos (2009), esta concepção sobre a deficiência ainda é a mais reforçada no Brasil.

Ajuda é outro elemento comum e forte nos grupos, pois aparece como elemento do núcleo central das representações sociais em ambos os grupos: no objeto Pessoa com Deficiência, com também no núcleo central do objeto Deficiência no GSD. Isso pode indicar que o entendimento está envolto nos constructos do amparo, do cuidado, do pegar no colo, e como diz Goffman (1980) quando há o estigma o indivíduo é percebido pelo traço que o difere dos demais e logo se resume a este traço que se destaca e impede que outros atributos sejam percebidos.

O Preconceito é outro elemento presente nas evocações livres e nas questões abertas em ambos os grupos. A falta de maior impacto do preconceito aparecendo na tarefa de evocação livre pode indicar uma tentativa de lidar com uma questão extremamente normativa em nossa sociedade. Mas, o aparecimento com grande frequência da categoria Relações de Convivência em se tratando das dificuldades enfrentadas pelas pessoas com deficiência revela a preocupação com o preconceito e a discriminação que não apareceram prioritariamente na primeira etapa do instrumento.

Nesse sentido, as pessoas não associaram de forma prioritária preconceito a deficiência e a pessoa com deficiência, fruto do impacto das lutas sociais de inclusão e a ampliação de políticas públicas que visam estreitar as relações sociais e garantir os direitos de cidadania às pessoas com deficiência e, por isso, a grande normatividade do tema, mas mostraram o quanto o preconceito pode ser um verdadeiro entrave na vida das pessoas com deficiência (Lanna Júnior, 2010; Relatório Mundial sobre a Deficiência, 2012).

O preconceito ainda é um dos motivos colocados pelo GCD que impedem as pessoas com deficiência serem vistas como sujeitos que possuem suas próprias habilidades, desejos, sonhos, sentimento. Interessante acrescentar aqui que o Preconceito apareceu nas unidades 
de contexto no GSD como exercido pelas próprias famílias que tem pessoas com deficiência em seu núcleo, já que ao tentarem proteger, acabam por esconder do convívio social.

O último elemento comum aos grupos é Superação, que pode apresentar dois sentidos: o sentido de se superar em relação as dificuldades externas e internas, ou no sentido de autoafirmação, com a preocupação de demonstrar ao outro de que é capaz. 0 GCD dialoga com a superação no sentido de não prostração diante das dificuldades, o que é reforçado nas questões abertas como um facilitador principalmente nas categorias Relações de convivência, em que se percebeu nos discursos a Superação no sentido de envolver a pessoa com deficiência em atividades físicas, nos esportes paraolímpicos e na rotina de exercícios de reabilitação. O GSD percebe a necessidade de superação da pessoa com deficiência com a necessidade de corresponder à expectativa do que é socialmente aceito e aprovado.

Essa expectativa é social e atinge inclusive as famílias que tem entes com deficiência, segundo Glat $(1996,2004)$ as famílias entram em conflito muitas vezes em fases de desenvolvimento de vida em que seu filho com deficiência não acompanha ou não se desenvolve como o esperado por esse familiar. Isso é vivido como um processo de luto que está ligado a pressão social de ter um filho correspondendo ao comportamento dito normal.

Há outros elementos que aparecem no núcleo central das evocações livres nos objetos e que não são comuns aos grupos, como o elemento Denominações de Deficiências que diz respeito aos tipos de deficiência ou sua classificação em: deficiência auditiva, deficiência visual, deficiência intelectual e deficiência motora ou deficiência múltipla, que aparece somente no GCD nos dois objetos Deficiência e Pessoa com Deficiência. Este elemento está fortemente evocado no GCD, o que indica que há o conhecimento sobre as nomenclaturas, tipologias e denominações a respeito de Deficiências e que desde muito cedo, na hora do diagnóstico, enfatizada por Glat (1996) e Omote (1994), o familiar entra em contato com esses conhecimentos do universo reificado.

No GSD aparecem outros elementos no núcleo central, além dos que já comentados acima, que não aparecem no outro grupo. No objeto Deficiência estão presentes elementos: Cuidado, Preconceito, Falta e Incapacidade. Estes elementos aparecem também nas questões abertas neste grupo relacionado a fatores que dificultam a vida das pessoas com deficiência na categoria Relações de Convivência com $60 \%$ de frequência das respostas, compreendendo todos estes elementos nos discursos deste grupo, o que indica que para o grupo o objeto Deficiência ainda está relacionado à visão do físico, ligado ao corpo, apontada por diversos autores (Silva, 1987; Diniz, Barbosa \& Santos, 2009; Sassaki, 2003). No objeto Pessoa com Deficiência aparece o elemento Exclusão, este elemento nas questões abertas também está incluído na categoria Relações de Convivência que recebe $60 \%$ de frequência, indicando que a exclusão ainda é uma realidade percebida pelo grupo e é um fator de dificuldade para as pessoas com deficiência.

\section{Considerações finais}

Numa visão ampliada, a semelhança nos grupos está em reconhecer que os fatores que dificultam a vida das pessoas com deficiência estão ligados a três principais categorias: Relações de Convivência, Infraestrutura/Acessibilidade e políticas públicas, nestas encontramos os prováveis elementos que aparecem nos núcleos centrais ou na primeira 
periferia das representações nas evocações livres, são eles: Dificuldade, Limitação, Superação e Preconceito.

Já os fatores que facilitam (ou poderiam facilitar) as representações sociais dos grupos se concentram nas políticas públicas e, nas evocações, ao falar da premência do amor e da ajuda.

De outro modo a principal diferença entre os grupos está nas reais necessidades e em como é visto a pessoa com deficiência e a própria família.

As representações sociais da deficiência e a da pessoa com deficiência estão vinculadas a idéia de dificuldade, limitação, ajuda, amor, superação e denominações sobre as deficiências. Ou seja, a deficiência e a pessoa ainda estão sob uma passividade e dependência e, apesar de começarem a ser percebida como sujeitos para além da deficiência (Glat, 1994, 1996; Omote, 1994), essa percepção ainda está atravessada pelo modelo médico, biológico sobre a deficiência (Diniz, Barbosa \& Santos, 2009; Silva, 2011). A família é apontada como a principal responsável sobre a pessoa com deficiência e seu desenvolvimento.

Identificar as representações sociais permeadas pela vivência direta ou não com a pessoa com deficiência permitiu avançar no conhecimento sobre o pensamento social que pode estar provocando ações de inclusão ou discriminação na sociedade brasileira em tempos de grande normatividade sobre esse tema.

A comparação entre grupos e a utilização de objetos que se diferenciavam pela inclusão da humanização da deficiência permitiram uma visão mais sofisticada das estruturas das representações sociais e seus pontos de convergência e divergência.

O presente estudo não esgota o tema, mas aponta profícuas reflexões acerca da importância dessa temática no escopo teórico da psicologia social para se perceber se, assim como outros temas normativos, a sociedade reconfigura cognitivamente os conceitos sobre a deficiência ou procura subterfúgios que permitam como aponta Pereira \& Vala (2010) que o preconceito e a dificuldade em lidar com as diferenças continuem se manifestando de forma sútil ou justificada.

\section{Referências}

Abric, J. C. (1994). Pratiques socialis y representaciones. México: Filosofia y Cultura Contemporanea.

Almeida, S., \& Naiff, L. A. M. (2011). Inclusão educacional nas representações sociais de professores e estudantes de magistério. Pesquisas e Práticas Psicossociais, 6(1), 29-38.

Ariès, P. (1981). História social da criança e da família (2a ed.). Rio de Janeiro: LTC.

Bardin, L. (2010). Análise de Conteúdo. Lisboa: Edições 70.

Brasil (2008). Decreto no 186, de 09 de julho de 2008. Aprovou a CDPD - Convenção sobre os direitos das pessoas com deficiência e seu protocolo facultativo, em 30 de março de 2007 em Nova York. Brasília, DF. Recuperado em 10 dezembro, 2012, de http:www.pessoacomdeficiencia.gov.br.

Cavalcante, F. G. (2003). Pessoas muito especiais: a construção social do portador de deficiência e a reinvenção da família. Rio de Janeiro: FIOCRUZ.

Diniz, D., Barbosa, L., \& Santos, W. R. dos. (2009). Deficiência, direitos humanos e justiça. Revista Internacional de Direitos Humanos, 6(11), 65-77. 
Freire-Costa, J. (1979). Ordem médica e norma familiar. Ed. Graal.

Glat, R. (1994). A integração dos portadores de deficiência: uma questão psicossocial. Recuperado em setembro, 2012, de http://pepsic.bvsalud.org/scielo.php?pid=\$1413389X1995000200010\&script=sci_arttext.

Glat, R. (1996). O papel da família na integração do portador de deficiência. Recuperado em setembro, 2012, de http://educa.fcc.org.br/pdf/rbee/v02n04/v02n04a10.pdf.

Glat, R. (2004). Uma família presente e participativa: o papel da família no desenvolvimento e inclusão social da pessoa com necessidades especiais. Anais do 9o Congresso Estadual das APAEs de Minas Gerais, Belo Horizonte, MG, Brasil.

Goffman, E. (1980). Estigma: notas sobre a manipulação da identidade deteriorada. Rio de Janeiro: Zahar.

Jodelet, D. (1998). Représentations sociales: um domaine em expansion. In D. Jodelet (Org.). Les Representations Sociales (pp. 31-61). Paris: PUF.

Jodelet, D. (2001). As representações sociais. Rio de Janeiro: Eduerj.

Jodelet, D. (2011). A fecundidade múltipla da obra “A psicanálise, sua imagem e seu público". In A. M. de O. Almeida, M. de F. de S. Santos \& Z. A. Trindade (Orgs.). Teoria das representações sociais: 50 anos (pp. 305-332). Brasília: Technopolitik.

Jodelet, D. (2005). Loucuras e representações sociais. Petrópolis: Vozes.

Lanna Júnior, M. C. M. (Comp.) (2010). História do Movimento Político das Pessoas com Deficiência no Brasil Brasília: Secretaria de Direitos Humanos. Secretaria Nacional de Promoção dos Direitos da Pessoa com Deficiência.

Moscovici, S. (1981). A representação social da psicanálise. Rio de Janeiro: Zahar.

Moscovici, S. (2012). A Psicanálise, sua imagem e seu público (S. Fuhrmann, Trad.). Petropólis: Vozes (Obra original publicada em 1961).

Lo Monaco, G., \& Lheureux, F. (2007). Reprèsentations sociales: théorie du noyau central et méthodes d'étude. Revue électronique de Psychologie Sociale, (1), 55-64.

Lo Monaco, G., Lheureux, F., \& Halimi-Falkowicz, S. (2008). Test d'independence au contexte (TIC) et structure des représentations sociales. Swiss Journal of Psychol., 67(2), 119-123.

Naiff, L. A. M, Sá, C. P., \& Naiff, D. G. M. (2005). Exclusão social nas memórias autobiográficas de mães e filhas In Anais da IV Jornada Internacional e II Conferência Brasileira sobre Representações Sociais (pp. 12331247). João Pessoa: Editora da Universidade Federal da Paraíba.

Omote, S. (1994). Deficiência e não-deficiência: recortes do mesmo tecido. Revista Brasileira de Educação Especial, 1(2), 65-74.

Palmonari, A., \& Cerrato, J. (2011). Representações sociais e psicologia social. In A. M. de O. Almeida, M. de F. de S. Santos \& Z. A. Trindade (Orgs.). Teoria das representações sociais: 50 anos (pp. 305-332). Brasília: Technopolitik.

Pan, M. A. G. S. de. (2008). O direito à diferença: uma reflexão sobre deficiência intelectual e educação inclusiva. Curitiba. Ibepex.

Pereira, C., \& Vala. J. (2010). Do preconceito à discriminação justificada. In-Mind Português, 1(2-3), 1-13.

Relatório mundial sobre a deficiência. (2012). World Health Organization, The World Bank. (Lexicus Serviços Lingüísticos, Trad.) São Paulo: SEDPCD.

Rocha-Coutinho, M. L. (1994). Tecendo por trás dos panos: A mulher brasileira nas relações familiares. Rio de Janeiro: Rocco Editora.

Sá, C. P. de. (1996). Núcleo central das representações sociais. Petrópolis: Vozes.

Sassaki, R. K. (2003). Terminologia da Deficiência na Era da Inclusão. In V. Virata (Coord.). Mídia e Deficiência (pp. 160-164). Brasília: Andi, Fundação Banco do Brasil.

Silva, O. M. (1987). Epopéia Ignorada: a pessoa deficiente na história do mundo de ontem e de hoje. São Paulo: Cedas. 
Silva, A. M. F. (2011). Representações sociais da família sobre a deficiência física da criança e suas implicações no cotidiano. Tese de doutorado, Florianópolis, SC, Brasil, 211p.

SMPD- Secretaria Municipal de Pessoas com Deficiência. Recuperado em novembro, 2012, de http://www.rio.rj.gov.br/web/smpd/exibeconteudo?article-id=151369.

SNPD- Secretaria Nacional de Pessoas com Deficiência. Recuperado em novembro, 2012, de http://www.pessoacomdeficiencia.gov.br.

Wachelke, J., \& Wolter, R. (2011). Critérios de construção e relato da análise prototípica para representações sociais. Psicologia: Teoria e pesquisa, 27(4), 521-526.

Walchelke, J. (2013). Beyond social representations: the conceptual bases of the structural approach on social thinking. Interamerican journal of psychology, 47(1), 131-138.

Vala, J. (2004). Representações sociais e psicologia social do conhecimento quotidiano. In J. Vala \& M. B. Monteiro. Psicologia Social (pp. 457-502). Lisboa: Fundação Calouste Gulbenkian.

Vergès, P. (2005). A evocação do dinheiro: um método para a definição do núcleo central de uma representação. In A. S. P. Moreira, B. V. Camargo, J. C. Jesuíno \& S. M. Nóbrega (Orgs.). Perspectivas teórico-metodológicas em representações sociais (pp. 471-488). João Pessoa: Editora UFPB. 